\title{
MODEL PENGEMBANGAN USAHA PERIKANAN YANG BERSINERGI DENGAN FUNGSI KONSERVASI KAWASAN (STATUS KASUS PENGELOLAAN SERO BERKANTONG DI PERAIRAN TELUK TIWORO, PROVINSI SULAWESI TENGGARA)
}

\author{
(Development Model of Fisheries Effort Compatible with Conservation Function of \\ Area (Case Study About Management of Sero Which Have Bag In Territorial Water of \\ Tiworo Bay, Province of South-East Sulawesi))
}

Mustaruddin ${ }^{1}$

ABSTRACT

\begin{abstract}
Utilization of fisheries resources in territorial water of Tiworo Bay have tendency to destructive and pursuing only economic benefit, though the territorial water have been expressed by as area of sea conservation pursuant to SK of Head of Muna Regency No. 157 Year 2004. This research aim to knowing compatibility of sero have bag with characteristic territorial water, dynamic pattern of optimation its use, and elegibility of sero have bag effort in Tiworo Bay. Reseach method are analysis of according to (Jusuf, 1999 and Mustaruddin, 2005), analysis of dynamic systems (Mubammadi, et. al, 2001), and effort analysis (Gaspersz, 1992). Result of the research show sero have bag as compatible with environmental friendliness character of catch appliance $(N K=3,4)$, potency of fisheries resources $(N K=3,0)$, requirement of socialize $(N K=3,3)$, law peripheral $(N K=3,2)$. Optimal amount of sero have bag which can be operated dynamicly in territorial water of Tiworo Bay about 15 unit. Effort of sero have bag can conducive to clean advantage $(\pi)$ which are positive, that are about $\mathrm{R} p 70.716 .800$ per month. If member of fisherman sero organizer amount to 15 people, bence each people will get bolder about Rp 4.714 .453 per month.
\end{abstract}

Keywords : dynamic, advantage, conservation, sero have bag

\begin{abstract}
ABSTRAK
Pemanfaatan sumberdaya ikan di perairan Teluk Tiworo cenderung destruktif dan hanya mengejar manfaat ekonomis, meskipun perairan tersebut telah dinyatakan sebagai kawasan konservasi laut berdasarkan SK Bupati Kabupaten Muna No. 157 Tahun 2004. Penelitian ini bertujuan mengetahui kesesuaian sero berkantong dengan karakteristik perairan, pola dinamis optimasi penggunaannya, dan kelayakan pengusahaan sero berkantong di Teluk Tiworo. Metode yang digunakan dalam penelitian meliputi analisis kesesuaian (Jusuf, 1999 dan Mustaruddin, 2005), analisis sistem dinamis (Muhammadi, et. al, 2001), dan analisis usaha (Gaspersz, 1992). Hasil penelitian menunjukkan sero berkantong sesuai dengan sifat alat tangkap ramah lingkungan $(\mathrm{NK}=3,4)$, potensi sumberdaya ikan kawasan $(\mathrm{NK}=3,0)$, kebutuhan masyarakat $(\mathrm{NK}=3,3)$, perangkat hukum terkait $(\mathrm{NK}=3,2)$. Jumlah optimal sero berkantong yang dapat dioperasikan secara dinamis di perairan Teluk Tiworo sekitar 15 unit. Pengusahaan sero berkantong dapat mendatangkan keuntungan bersih $(\pi)$ yang positif, yaitu sekitar Rp 70.716 .800 per bulan. Bila nelayan anggota pengelola sero berkantong berjumlah 15 orang, maka setiap anggota akan mendapat bagi hasil sekitar Rp 4.714 .453 per bulan.
\end{abstract}

Kata kunci : dinamis, keuntungan, konservasi, sero berkantong

\section{PENDAhUluan}

Perairan laut Indonesia yang dikenal sebagai negara mega-biodiversity, baik dari segi keanekaragaman sumberdaya sumberdaya ikan, biota laut non ikan, maupun keanekaragaman ekosistemnya. Di satu sisi memang cukup membanggakan, namun dari sisi yang lain menuntut adanya tanggung jawab yang sangat besar. Menurut Charles (2001), terjaganya keseimbangan antara kelestarian fungsi (ekologis) dan kelestarian manfaat (ekonomis) keanekaragaman sumberdaya ikan perlu menjadi tugas dan tanggung jawab yang harus dipertahankan keberlanjutannya.

Upaya konservasi keanekaragaman sumberdaya ikan dan biota laut lainnya termasuk telah lama dilaksanakan di Indonesia sebelum ditetapkannya UndangUndang Nomor 5 Tahun 1990 tentang Konservasi Sumber Daya Alam Hayati.

\footnotetext{
${ }^{1}$ Staf Pengajar Departemen PSP, FPIK IPB
} 
Sesuai dengan Undang-undang Nomor 31 Tahun 2004 tentang Perikanan, maka Departemen Kelautan dan Perikanan dalam upayanya mengelola kawasan konservasi laut terus mengembangkan pengelolaan yang dapat diterima masyarakat kawasan agar tujuan melakukan konservasi dapat berjalan secara optimal.

Pengelolaan kawasan konservasi laut di Indonesia dari sisi kualitas dan integritas kawasan konservasi laut tersebut masih jauh dari layak, bahkan dari waktu ke waktu semakin menurun. Terdapat beberapa masalah yang mendasar yang dihadapi dalam pengelolaan kawasan konservasi laut termasuk perairan Teluk Tiworo. Salah satunya adalah pola pemanfaatan sumberdaya ikan oleh nelayan dan masyarakat setempat yang belum bersinergi dengan fungsi konservasi yang melekat pada kawasan kawasan konservasi laut. Selama ini pemanfaatan sumberdaya ikan cenderung destruktif dan hanya mengajar manfaat ekonomis semata, meskipun perairan tersebut berdasarkan SK Bupati Kabupaten Muna No. 157 Tahun 2004. Akibatnya, sumberdaya ikan dan ekosistem perairan kawasan tersebut semakin tertekan hingga fungsi konservasi yang melekat pada perairan tersebut terancam

Untuk menghindari meluasnya kerusakan tersebut tanpa menghilangkan upaya pemanfaatan yang sudah berlangsung, maka perlu dirancang pola pemanfaatan yang mengembangkan alat tangkap yang bersesuaian dengan karakteristik perairan Teluk Tiworo dan layak/menguntungkan bila diusahakan oleh nelayan. Salah satu alat tangkap yang bisa diandalkan untuk maksud ini adalah sero berkantong. Sero berkantong dianggap sebagai alat tangkap yang ramah lingkungan, terkendali, dan dapat melibatkan nelayan setempat secara luas dalam melakukan penangkapan di zona pemanfaatan kawasan konservasi laut sebagai alternatif mata pencaharian masya-rakat. Penelitian ini akan mencoba memas-tikan hal tersebut dan melihat tingkat kesesuaian, kelayakan diusahakan dan kemungkinan optimal sero berkantong bila diusahakan lebih luas di perairan Teluk Tiworo.

Tujuan penelitian ini adalah :

1. Mengetahui kesesuaian sero berkantong dengan karateristik perairan Teluk Tiworo sebagai kawasan konservasi laut.
2. Mengetahui pola dinamis optimasi penggunaan sero berkantong dalam pemanfaatan sumberdaya ikan di Teluk Tiworo.

3. Mengetahui kelayakan usaha perikanan sero berkantong di Teluk Tiworo.

\section{METODOLOGI}

\subsection{Waktu dan Tempat Penelitian}

Penelitian ini dilaksanakan di Teluk Tiworo, Muna, Propinsi Sulawesi Tenggara. Teluk Tiworo menjadi andalan dapat penangkapan berbagai jenis ikan potensial bagi Kabupaten Muna. Penelitian ini dilak-sanakan selama 5 (lima) bulan dimulai dari bulan Nopember 2007 sampai dengan Maret 2008.

\subsection{Jenis Data dan Metode Pengum- pulan Data}

Data yang dikumpulkan dalam penelitian ini terdiri dari data primer dan data sekunder. Data primer terdiri yang dikumpulkan meliputi data karakteristik perairan Teluk Tiworo, potensi sumberdaya ikan dan biota laut lainnya, alat tangkap, data finansial usaha perikanan tangkap, data profil nelayan, dan lainnya. Sedangkan data sekunder terdiri dari data time series produksi perikanan, data perkembangan alat tangkap, data peraturan hukum dalam pengelolaan Teluk Tiworo, dan lainnya. Data primer dikumpulkan melalui pengamatan langsung di lapang, pengisian kuesioner, dan diskusi dengan pihak-pihak terkait. Sedangkan data sekunder dikumpulkan dari laporan kegiatan di istansi terkait, literatur, dan hasil penelitian yang relevan.

\subsection{Metode Analisis Data}

\subsubsection{Analisis kesesuaian}

Analisis kesesuaian merupakan analisis yang bersifat multdimensional karena kesesuaian obyek pemanfaatan dengan pola pemanfaatan dilihat dari berbagai aspek yang terkait. Dalam analisis ini, pola pemanfaatan difokuskan pada sero berkantong sebagai alat tangkap yang menggabungkan sifat positif sero dan bubu yang selama ini banyak digunakan oleh nelayan di Teluk Tiworo. Dalam kaitan dengan fungsi konservasi yang melekat pada perairan Teluk Tiworo, maka analisis ini mencakup aspek kesesuaian dengan sifat/alat tangkap ramah lingkungan, kesesuaian dengan potensi sumberdaya ikan kawasan, kesesuaian 
dengan kebutuhan masyarakat, dan mendapat dukungan secara kelembagaan. Dengan mengacu kepada Jusuf (1999) dan Mustaruddin (2005), adapun kriteria penilaiannya : (a) Kesesuaian dengan sifat sarana ramah lingkungan, dapat dilihat dari sifat selektif yang melanggar fungsi kawasan, jaminan terhadap ekosistem, dampak terhadap biodiversity, perlindungan terhadap biota dasar, dan daya cemar terhdap kawasan; (b) Kesesuaian dengan potensi sumberdaya ikan kawasan, dilihat dari jenis ikan yang ditangkap meng-gunakan unit penangkapan, daya dukung di lokasi, dan nilai ekonomisnya; (c) Kesesuaian dengan kebutuhan masyarakat, dilihat dari kepraktisannya, biaya operasi, keefektifan, kekuatan, kemudahan transfer knowlegde, dan tingkat keuntungan dari operasi unit penangkapan tersebut; dan (d) Kesesuaian dengan perangkat hukum terkait, baik berupa Undang-Undang, Peraturan Pemerintah, Surat Keputusan Kepala Daerah, dan lainnya yang berlaku di lokasi. Sedangkan nilai kesesuaian (NK) terhadap kriteria tersebut diberikan dengan ketentuan nilai 1 bila tidak sesuai, nilai 2 bila kurang sesuai, nilai 3 bila sesuai, dan nilai 4 bila sangat sesuai.

\subsubsection{Analisis sistem dinamis}

Analisis sistem dinamis ini dilakukan untuk mengetahui pola dinamis optimasi penggunaan sero berkantong dalam pemanfaatan sumberdaya perikanan sebagai sebuah sistem pemanfaatan. Pola dinamis yang dimaksud adalah perilaku jumlah sero berkantong yang bisa dioperasikan optimum dan dinamis, namun tidak meleibih daya dukung yang ada terutama dari aspek potensi sumberdaya. Hal ini penting supaya fungsi konservasi yang melekat pada perairan Teluk Tiworo tetap terjamin meskipun cukup kaya dengan sumberdaya ikan yang potensial. Analisis sistem dinamis ini dilakukan menggunakan Program Powersim 2.5C (Muhammadi, et. al, 2001). Sedangkan data pendukung yang digunakan dapat dipersiapkan menggunakan Program MS Excell. Adapun Program Powersim $2.5 \mathrm{C}$ yang digunakan dalam analisis diilustrasikan adalah :

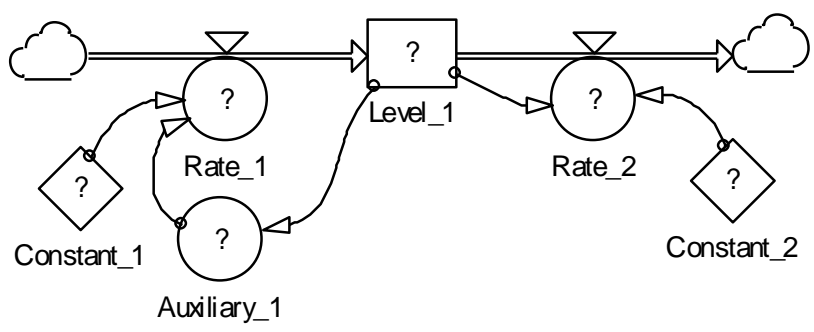

Gambar 1. Ilustrasi analisis sistem dinamis menggunakan Program Powersim 2.5C

Pada Gambar 1, level digunakan untuk mengakumulasi perubahan perila$\mathrm{ku}$, rate digunakan untuk transfomasi perubahan, auxiliary digunakan mengakomodir interaksi dari peubah/komponen lain dalam sistem dinamis, constant digunakan untuk nilai komponen interaksi yang bersifat tetap, source dan sink (tanda awan) digunakan sebagai pembatas sistem dinamis yang digunakan diawal dan diakhir interaksi komponen sistem, tanda panah mencirikan interaksi/hubungan diantara peubah/komponen.

\subsubsection{Analisis usaha}

Analisis usaha ini dimaksudkan untuk mengetahui apakah sero berkantong menguntungkaan atau tidak dalam pengusahaannya. Analisis usaha disusun dengan melihat perbedaan antara total revenue (TR) dengan total cost (TC) sebagai keuntungan bersih (Gaspersz, 1992).

Rumus perhitungannya adalah :

$$
\begin{aligned}
& \mathrm{TR}=\sum \mathrm{pxC} \\
& \mathrm{TC}=\sum \mathrm{c} \times \mathrm{E} \\
& \Pi=\mathrm{TR}-\mathrm{TC}
\end{aligned}
$$

Dimana :

$\mathrm{TR}=$ total revenue (total penerimaan) (Rp)

$\mathrm{p}=$ harga jual ikan $(\mathrm{Rp} / \mathrm{kg})$

$\mathrm{C}=$ hasil tangkapan rata-rata per trip $(\mathrm{kg})$

$\mathrm{TC}=$ total cost (total biaya operasi) $(\mathrm{Rp})$

$\mathrm{c}$ = biaya rata-rata yang dikeluarkan (Rp/trip) 


\section{$\mathrm{E}=$ frekuensi penangkapan (trip) \\ $\Pi=$ keuntungan bersih $(\mathrm{Rp})$}

\section{HASIL DAN PEMBAHASAN}

\subsection{Kesesuaian Sero Berkantong dengan Karakteristik Kawasan}

Hasil analisis data lapang menunjukkan bahwa sero berkantong mempunyai kesesuaian dengan sifat alat tangkap ramah lingkungan $(\mathrm{NK}=3,4)$, kesesuaian dengan potensi sumberdaya ikan kawasan $(\mathrm{NK}=3,0)$, kesesuaian dengan kebutuhan masyarakat $(\mathrm{NK}=3,3)$ dan perangkat hukum terkait $(\mathrm{NK}=3,2)$. Adapun rincian kesesuaian sero berkantong dengan fungsi konservasi yang melekat pada Teluk Tiworo adalah : (a) Selektif dalam penangkapan ikan $(\mathrm{NK}=3,4)$ karena mata jaring dapat meloloskan ikan kecil yang belum layak tangkap. Disamping itu, bila jenis ikan lain yang dilindungi tertangkap dapat dilepaskan kembali melalui pintu keluar kantong, (b) Tidak merusak ekosistem terumbu karang $(\mathrm{NK}=3,8)$ karena tidak ada penancapan/penggalian karang dalam pemasangannya, (c) Dampak negatif terhadap biodiversity rendah $(\mathrm{NK}=3,6)$ karena meloloskan ikan kecil/generasi baru dan tidak ada penggunaan bahan pemusnah (misal bahan peledak dan bahan racun), (d) Tidak membahayakan pergerakan biota tingkat dasar (fitoplankton, zooplankton, benthos) $(\mathrm{NK}=3,1)$ karena selalu dapat lewat pada mata jaring yang diam, dan (e) operasinya tidak mencemari perairan $(\mathrm{NK}=3,1)$, karena tidak menggunakan bahan bakar, listrik/panas, dan oli yang sewaktu-waktu limbahnya bisa terbuang ke laut.

Sero berkantong dapat menangkap berbagai jenis ikan terutama ikan yang mempunyai mobilitas tinggi $(\mathrm{NK}=3,2)$, misalnya ikan kakap, lencam, kurisi, tembang, tongkol, kembung, layang, selar, dan lain-lain (Tabel 1). Sedangkan ikanikan tersebut termasuk sumberdaya ikan yang diperbolehkan ditangkap (bukan ikan langka yang dilindungi) dan banyak terdapat di Teluk Tiworo $(\mathrm{NK}=3,1)$. Disamping itu, juga menjadi komoditas unggulan bagi Kabupaten Muna (NK = $2,8)$.

Tabel 1. Produksi beberapa jenis ikan dan statusnya periode 5 tahun di Muna

\begin{tabular}{|c|c|c|c|c|c|c|c|}
\hline \multirow[t]{2}{*}{ No. } & \multirow{2}{*}{$\begin{array}{l}\text { Jenis } \\
\text { Ikan }\end{array}$} & \multicolumn{5}{|c|}{ Produksi (ton/tahun) } & \multirow[t]{2}{*}{ Status Komoditas } \\
\hline & & 2002 & 2003 & 2004 & 2005 & 2006 & \\
\hline 1 . & Lencam & $1.771,6$ & $1.663,9$ & $1.777,2$ & 81,1 & $1.569,8$ & Komoditas unggulan \\
\hline 2. & Kakap & 264,1 & 701,5 & 829,2 & 582,1 & 453,6 & Komoditas unggulan \\
\hline 3. & Kurisi & $1.944,3$ & 889,0 & 984,2 & - & 222,4 & Komoditas unggulan \\
\hline 4. & Tembang & $1.317,9$ & $1.673,7$ & 895,8 & $1.673,7$ & $1.036,3$ & Komoditas unggulan \\
\hline 5. & Tongkol & $1.925,5$ & 947,6 & 740,7 & 947,6 & 927,4 & Komoditas unggulan \\
\hline 6. & Kembung & $7.744,2$ & $2.896,6$ & $2.820,5$ & $2.896,6$ & $4.202,9$ & Komoditas unggulan \\
\hline 7. & Layang & 873,1 & 929,9 & $1.723,4$ & 929,9 & $1.464,1$ & Komoditas unggulan \\
\hline 8. & Selar & $1.510,2$ & $1.802,7$ & $1.891,9$ & $1.802,7$ & $1.999,1$ & Komoditas unggulan \\
\hline
\end{tabular}

Sumber : Dinas Perikanan dan Kelautan Kabupaten Muna ( 2007) dan berbagai sumber

Sero berkantong merupakan kombinasi alat tangkap sero dan bubu (kantong) yang menggabungkan sifat-sifat positifnya dan mereduksi sifat-sifat negatifnya. Oleh karena sero dan bubu banyak di pakai di Teluk Tiworo, maka sero berkantong menjadi kebutuhan dan harapan masyarakat. Adapun manfaat lebih sero berkantong bagi masyarakat adalah : (a) praktis dan ekonomis dalam operasinya karena tidak perlu ditunggu dan tidak menggunakan bahan bakar, listrik atau sejenisnya $(\mathrm{NK}=3,5)$, (b) dapat menangkap ikan target dalam jumlah besar (efektif) karena dilengkapi dengan pengarah ikan $(\mathrm{NK}=3,4)$, (c) lebih tahan lama daripada bubu yang terbuat dari bambu, karena dibuat dari bahan jaring yang kuat $(\mathrm{NK}=2,6)$, (d) lebih mudah dipelajari dan menyatu dengan kehidupan masyarakat karena secara prinsip tidak berbeda dengan sero dan bubu yang selama ini dipakai masyarakat $(\mathrm{NK}=3,8)$, dan (e) lebih menguntungkan karena hasil tangkapannya banyak $(\mathrm{NK}=3,2)$.

Sero berkantong mempunyai sifatsifat yang mendukung fungsi konservasi dan menjadi alat tangkap alternatif pada lokasi yang rusak. Sifat-sifat ini sangat diharap-kan dan dalam kalitan dengan dukungan secara kelembagaan, penggunaan sero berkantong bersesuaian dengan; (a) SK Bupati Kabupaten Muna No. 157 Tahun 2004 tentang penunjukan Teluk 
Tiworo dan Pulau-Pulau sekitarnya sebagai kawasan wisata laut (minimal interaksinya yang merusak) $(\mathrm{NK}=3,2)$, (b) Undang-undang Nomor 5 Tahun 1990 tentang Konservasi Sumberdaya Alam dan Ekosistemnya, karena toleran terhadap lokasi terumbu karang yang rusak $(\mathrm{NK}=3,4)$, (c) Undang-undang Nomor 31 Tahun 2004 tentang Perikanan $(\mathrm{NK}=3,0)$, dan (d) Rancangan Peraturan Pemerintah tentang Konservasi Sumberdaya Alam $(\mathrm{NK}=3,2)$.

Sero berkantong merupakan alat tangkap yang tidak dirancang untuk mencari ikan ke sarangnya (kawasan lengkap komponen dasarnya), tetapi hanya menghadang ikan yang lewat. Meskipun penggunaan sero berkantong lebih fleksibel, namun untuk pelestarian kawasan Teluk Tiworo yang melekat fungsi konservasi, maka operasi sero berkantong lebih diarahkan pada perairan pulau dengan kondisi : (a) mempunyai dasar perairan yang relatif datar, (b) bila ukuran sero berkantong tidak terlalu besar, maka dapat dipasang pada perairan pantai kedalaman 3 - $6 \mathrm{~m}$, (c) bila ukuran sero berkantong besar (tingginya $>6 \mathrm{~m}$ ), maka dapat dipasang pada perairan pantai kedalaman 8 - $15 \mathrm{~m}$, (d) lebih dianjurkan pada lokasi dengan kondisi terumbu karang yang kurang baik dan masih terdapat penggunaan alat tangkap tidak ramah lingkungan seperti bubu tancap, pukat, dan bom. Perairan pulau dengan kondisi seperti ini diantaranya perairan Pulau Belanbelan Kecil, Pulau Balu, Pulau Tiga, Pulau Mandika, dan Pulau Bero.

\subsection{Pola Dinamis Optimasi Penggu- naan Sero Berkantong}

Menurut Undang-Undang Nomor 5 Tahun 1990 tentang Konservasi Sumberdaya Alam dan Ekosistemnya, pemanfaatan sumberdaya tertentu yang diperbolehkan dapat dilakukan di kawasan konservasi selama tidak mengancam kelestarian sumberdaya tersebut. Terkait dengan ini, maka sumberdaya ikan yang terdapat di kawasan Teluk Tiworo melekat fungsi konservasi di peraiarannya dapat juga dimanfaatkan oleh masyarakat sekitar yang sudah berpofesi sebagai nelayan. Pemanfaatan terbatas ini juga diatur menurut SK Bupati Kabupaten Muna No. 157 Tahun 2004 tentang penunjukan Teluk Tiworo dan Pulau-Pulau sekitarnya sebagai kawasan wisata laut. Terkait dengan ini, maka upaya pemanfaatan tersebut harus sesuai dengan daya dukung potensi yang ada (maximum sustainable yield//MSY). Menurut hasil studi Ditjen KPSK (2006) tentang fasilitasi sarana pemanfaatan biota laut yang berkelanjutan di KKLD yang lokasi pilot project-nya di Teluk Tiworo dinyatakan bahwa potensi lestari (MSY) untuk ikan-ikan dengan mobilitas tinggi sekitar $4.025 .000 \mathrm{~kg}$ per tahun. Gambar 2 menyajikan model dinamis optimasi penggunaan sero berkantong dihubungkan dengan daya dukung potensi sumberdaya ikan sasaran.

Bila model tersebut diintervensi menggunakan daya dukung ikan sasaran sebesar $80 \%$ dari MSY, maka akan didapatkan hasil analisis seperti pada Gambar 3a. Berdasarkan Gambar 3a, jumlah sero berkantong yang dioperasikan dapat dioptimalkan menjadi 23 unit. Menurut PEMDA Kabupaten Muna (2007), penangkapan ikan di Kabupaten Muna diharapkan tidak melebihi $50 \%$ dari potensi sumberdaya ikan yang ada. Hal ini dimaksudkan untuk menjaga fungsi konservasi sumberdaya yang melekat pada perairan Teluk Tiworo. Bila model Gambar 2 diintervensi menggunakan ketentuan ini, maka jumlah sero berkantong yang dioperasikan dapat dioptimalkan menjadi 15 unit (Gambar 3b). 


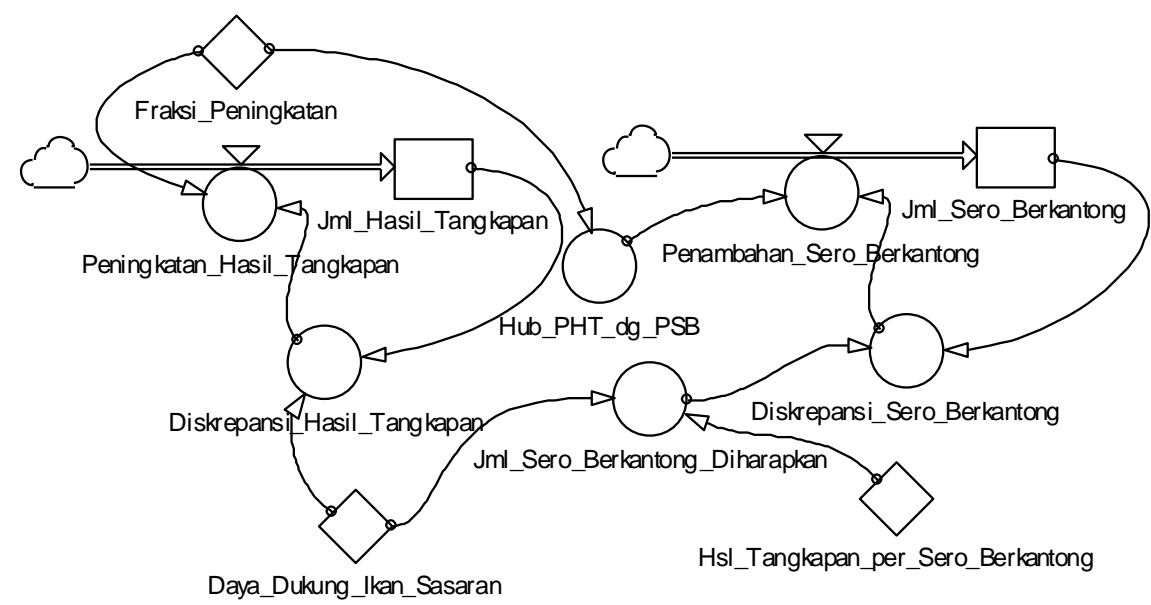

Gambar 2. Model dinamis optimasi penggunaan sero berkantong di perairan Teluk Tiworo

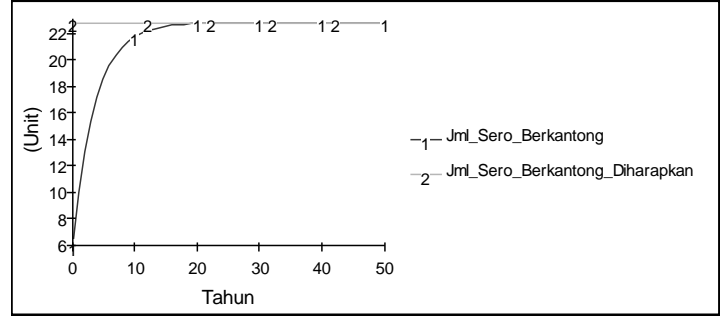

(a) Intervensi daya dukung $80 \% \mathrm{MSY}$

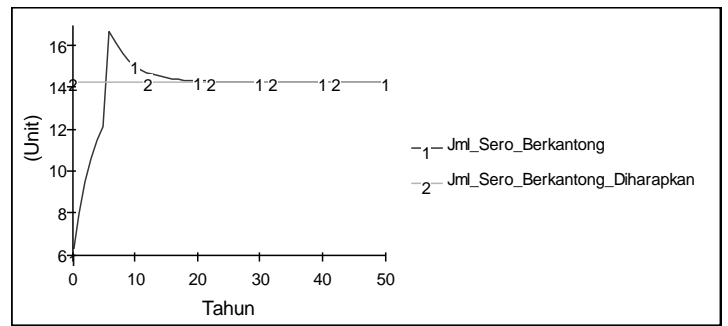

(e) Intervensi daya dukung $50 \% \mathrm{MSY}$ dan hibah 4 unit sero berkantong tahıun ke-5

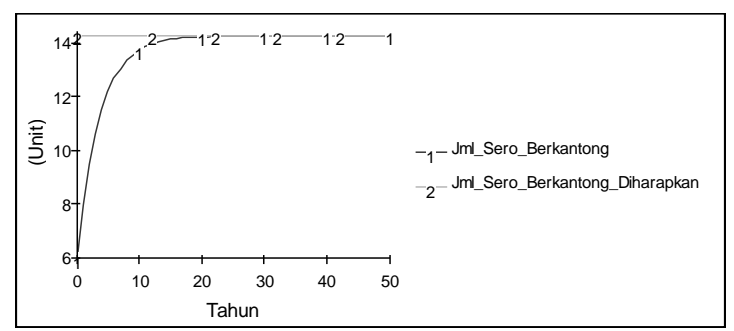

(b) Intervensi daya dukung $50 \% \mathrm{MSY}$

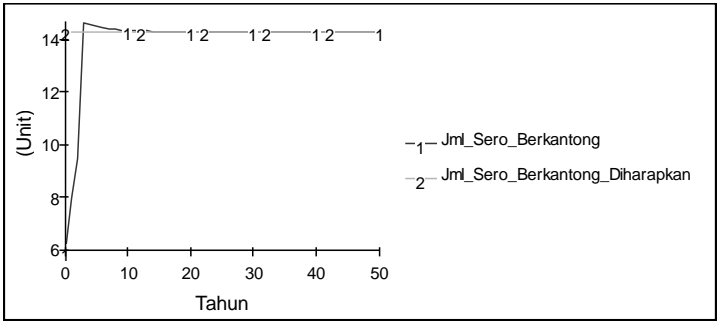

(d) Intervensi daya dukung $50 \% \mathrm{MSY}$ dan hibah 4 unit sero berkantong tahun ke-2

Gambar 3. Hasil analisis dinamis optimasi penggunaan sero berkantong di Teluk Tiworo

Bila model Gambar 2 yang menggunakan daya dukung $50 \%$ dari potensi sumberdaya ikan diintervensi lagi misal dalam bentuk adanya hibah 4 unit sero berkantong pada tahun ke-5, maka jumlah sero berkantong di Teluk Tiworo menjadi 18 unit (Gambar 3c). Jumlah ini melebihi jumlah sero berkantong yang diharapkan (15 unit). Untuk mempertahankan fungsi konservasi yang melekat pada perairan Teluk Tiworo, maka pada tahun berikutnya jumlah sero berkantong tersebut dikurangi (Gambar 3c) hingga tidak melebihi jumlah optimal. Sedangkan bila hibah tersebut dilakukan pada tahun ke-2, maka jumlah sero berkantong menjadi 15 unit (Gambar 3d) yang berarti tepat pada jumlah optimal sero berkantong yang diharapkan. Di Teluk Tiworo, intervensi-intervensi tersebut sangat mungkin terjadi sebagai upaya Pemerintah baik PEMDA Kabupaten Muna maupun Pemerintah Pusat untuk menjaga keles-tarian sumberdaya ikan dan fungsi konservasi yang melekat pada perairan Teluk Tiworo.

\subsection{Kelayakan Usaha Sero Berkantong}

Analisis kelayakan usaha ini merupakan upaya untuk mengetahui kelayakan atau kepantasan kegiatan pemanfaatan sumberdaya menggunakan sero berkantong (terutama financial position dan skala usaha) sehingga dapat 
diketahui feedback-nya bagi perekonomian nelayan dan masyarakat di sekitar Teluk Tiworo. Hasil analisis data lapang menunjukkan bahwa pengusahaan sero berkantong menghasilkan total penerimaan (TR) sekitar Rp 841.986 untuk setiap operasinya. Setiap hari biasanya dilakukan operasi 4 kali (setiap 5-6 jam) dan operasi tersebut dapat dilakukan sekitar 25 hari setiap bulannya. Total penerimaan tersebut merupakan akumulasi dari penerimaan hasil tangkapan berupa ikan kakap, selar, lencam, tongkol, tembang, kembung, dan layang. Penerimaan tertinggi berasal dari hasil tangkap ikan tongkol yaitu sekitar Rp 321.000 untuk setiap operasinya (Gambar 4). Hasil tang-kapan rata-rata ikan tongkol dari sero berkantong sekitar 42,8 $\mathrm{kg}$ dengan harga jual Rp 7.500/kg. Ikan kakap memberikan kontribusi urutan kedua dengan nilai sekitar Rp 150.750 untuk setiap operasinya. Hasil tangkapan sero berupa ikan kakap umumnya tidak banyak, yaitu sekitar 6,03 setiap operasinya, tetapi mempunyai harga jual tinggi yang mencapai Rp 25.000/kg. Ikan kakap biasanya ditangkap dan dijual dalam keadaan hidup kepada pengumpul ikan-ikan tujun ekspor di lokasi.

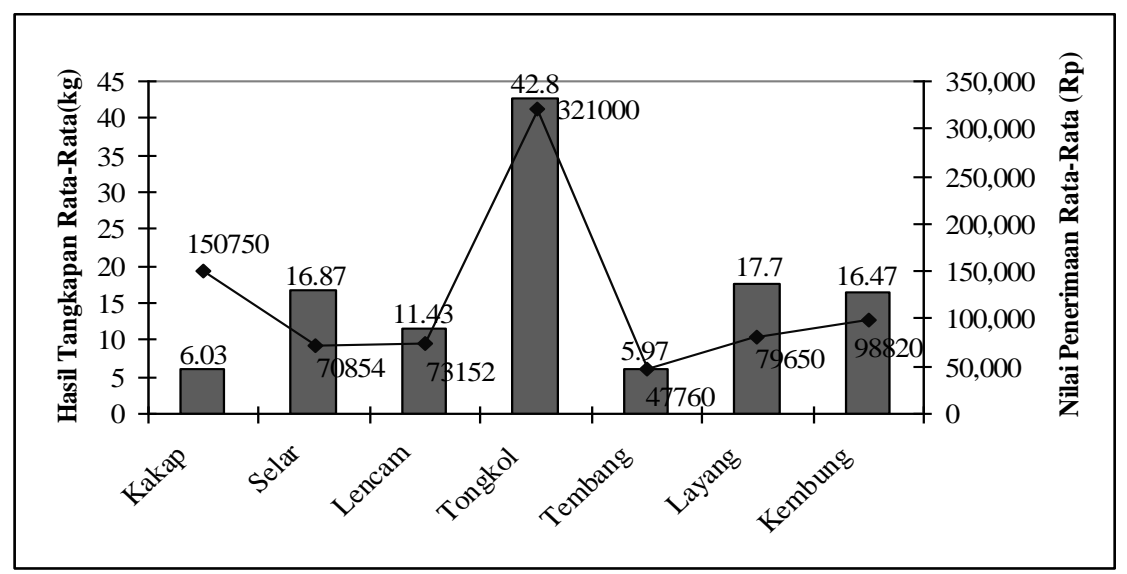

Gambar 4. Hasil tangkapan untuk setiap operasi sero berkantong di Teluk Tiworo

Sedangkan biaya total (TC) yang dikeluarkan untuk setiap operasi penangkapan mengunakan sero berkantong sekitar Rp 134.818. Biaya tersebut mencakup biaya biaya variabel, biaya tetap, dan biaya lain-lain yang dikeluarkan untuk mendukung operasi. Biaya lain-lain selama ini hanya berupa retribusi yang diserahkan kepada pihak PEMDA yang mengelola kawasan Teluk Tiworo yang nilainya sekitar $5 \%$ dari keuntungan. Biaya operasi ini termasuk cukup murah karena lokasi pemasangan sero berkantong cukup di perairan pulau dekat perkampungan nelayan. Disamping itu, operasi pengambilan hasil tangkapan yang terperangkap di rumpon cukup menggunakan kapal/perahu dayung yang umum dimiliki oleh nelayan karena. Dari atas perahu dayung tersebut, nelayan dapat mengambil hasil tangkap dengan menarik bagian kantong dari sero ke atas perahu. Biaya bahan makanan, BBM, dan merupakan komponen biaya dominan dalam operasi penangkapan menggunakan sero berkantong yaitu masing Rp 56.250,
Rp 20.000, dan Rp 11.000 untuk setiap operasinya. Setelah hasil tangkapan diambil, nelayan langsung membawa pulang supaya dapat langsung dijual secara segar atau dalam keadaan hidup untuk jenis ikan kakap dan lainnya. Tabel 2 menyajikan biaya variabel rata-rata untuk setiap operasi sero berkantong di Teluk Tiworo.

Bila melihat perimbangan total penerimaan dengan total biaya yang dikeluarkan, maka setiap operasi penangkapan menggunakan sero berkantong akan mendatangkan keuntungan bersih ( $\pi)$ yang positif, yaitu sekitar Rp 707.168 untuk setiap operasinya atau sekitar Rp 70.716 .800 per bulan. Bila nelayan anggota pengelola sero berkantong berjumlah 15 orang, maka setiap anggota akan mendapat bagi hasil sekitar Rp 4.714.453 per bulan. Bagi hasil ini termasuk besar dan akan sangat membantu bagi perekonomian nelayan dan masyarakat di kawasan Teluk Tiworo. 
Tabel 2. Biaya variabel untuk setiap operasi sero berkantong di Teluk Tiworo

\begin{tabular}{|c|l|c|c|c|c|}
\hline No. & \multicolumn{1}{|c|}{ Uraian } & Jumlah & Satuan & $\begin{array}{c}\text { Nilai Satuan } \\
(\mathrm{Rp})\end{array}$ & Total (Rp) \\
\hline 1. & Biaya bahan makanan & 1 & Paket & 56,250 & 56,250 \\
2. & Biaya BBM & 1 & Paket & 20,000 & 20,000 \\
3. & Biaya es & 1 & Balok & 11,000 & 11,000 \\
4. & Biaya perawatan alat tangkap & 1 & Paket & 2,000 & 2,000 \\
5. & Biaya docking & 1 & Paket & 1,437 & 1,437 \\
6. & Biaya perawatan mesin & 1 & Paket & 700 & 700 \\
7. & Bongkar muat (Rp 300/50 Kg) & 117 & Kg & 6 & 704 \\
\hline & Total biaya variabel & & & & 92,091 \\
\hline
\end{tabular}

Dengan mengacu kepada bagi
hasilnya, maka skala usaha sero
berkantong ini termasuk besar bila
anggota berjumlah 15 orang. Hasil diskusi
dengan masyarakat di Desa Bero Pulau Tiga menunjukkan bahwa penghasilan sekitar Rp 1.500 .000 per bulan sudah cukup bagi mereka untuk memenuhi berbagai kebutuhan hidup. Berdasarkan kriteria ini, maka sero berkantong ini dapat dioptimalkan peruntukkannya untuk skala anggota 45 orang nelayan dengan bagi hasil per anggota sekitar 1.571.484 per bulan. Di samping menangkap ikan, nelayan di Teluk Tiworo juga bertani dengan menanam berbagai jenis sayuran dan rempah-rempah, sehingga uang hasil tangkapan biasanya lebih banyak diperuntukkan bagi kebutuhan sandang dan biaya anak-anak sekolah.

\section{KESIMPULAN DAN SARAN}

\subsection{Kesimpulan}

Sero berkantong mempunyai kesesuaian dengan sifat alat tangkap ramah lingkungan $(\mathrm{NK}=3,4)$, potensi sumberdaya ikan $(\mathrm{NK}=3,0)$, kebutuhan masyarakat $(\mathrm{NK}=3,3)$, perangkat hukum terkait di perairan Teluk Tiworo $(\mathrm{NK}=3,2)$. Sero berkantong bersifat selektif, tidak merusak ekosistem terumbu karang, dampak negatif terhadap biodiversity rendah, tidak membahayakan pergerakan biota tingkat dasar, operasinya tidak mencemari perairan, tidak menangkap ikan yang dilindungi, praktis dan ekonomis dalam operasinya, efektif menangkap ikan target, lebih mudah dipelajari karena merupakan penggabungan sifat positif sero dan bubu yang selama ini dipakai masyarakat, bersesuaian dengan SK Bupati Kabupaten Muna No. 157 Tahun 2004, Undangundang Nomor 5 Tahun 1990 tentang
Konservasi Sumberdaya Alam dan Ekosistemnya, Undang-undang Nomor 31 Tahun 2004 dan lainnya.

Bila mengacu kepada arahan PEMDA Kabupaten Muna (2007) terkait pemanfaatan sumberdaya ikan yang tidak melebihi $50 \%$ dari potensi yang ada, maka jumlah optimal sero berkantong yang dapat dioperasikan di perairan Teluk Tiworo sekitar 15 unit. Seiring dengan dengan pengembangan tersebut, bila dilakukan penambahan secara dinamis 4 unit sero berkantong pada tahun ke-5 pengem-bangannya, maka jumlah sero berkantong yang ada melebihi batas optimal, sedangkan bila penambahan dilakukan pada tahun ke-2 tidak terjadi kelebihan. Pengusahaan sero berkantong dapat mendatangkan keuntungan bersih (п) yang positif, yaitu sekitar Rp 70.716.800 per bulan. Bila nelayan anggota pengelola sero berkantong berjumlah 15 orang, maka setiap anggota akan mendapat bagi hasil sekitar Rp 4.714.453 per bulan. Bagi hasil ini termasuk besar dan akan sangat membantu bagi perekonomian nelayan dan masyarakat di kawasan Teluk Tiworo.

\subsection{Saran}

Sebagai mata pencaharian alternatif (pengganti alat tangkap destruktif) bagi masyarakat nelayan di perairan Teluk Tiworo, maka sebaiknya pengembangan sero berkantong dilakukan secara bertahap. Untuk mengakomodir kekurangan alat tangkap tersebut sementara waktu, maka sero berkantong ( 6 unit) yang ada saat ini dapat dioptimalkan peruntukkannya untuk dari beranggotakan 15 menjadi 45 orang nelayan. Untuk mempercepat pengembangan, dapat dilakukan penggalangan dana mandiri dari masyarakat nelayan dan hibah pendamping dari PEMDA Kabupaten Muna. 


\section{DAFTAR PUSTAKA}

Adhuri, D. S. 1998. Who Can Challenge Them? Lesson Learned From Attempting to Curb Cyanide Fishing in Maluku, Indonesia. Life Reef Fish Information Bulletin No. 4 pp. $12-17$.

Berkes, F. 1994. Property Rights and Coastal Fisheries, p. 51-62. In Pomeroy, R.S. (ed.) Community Management and Common Property of Coastal Fisheries in Asia and The Pasific: concepts,methods and exeriences. ICLARM Conf. Proc. 45, $189 \mathrm{p}$.

Charles, A. T. 2001. Sustainable Fishery Systems. Blackwell Science. Canada.

Dinas Perikanan dan Kelautan Kabupaten Muna. 2005. Profil Pulau-Pulau Kecil Kabupaten Muna. Raha.

Direktorat Konservasi dan Taman Nasional Laut (KTNL). 2005. Manajemen Plan Kawasan Konservasi Laut Daerah (KKLD) Teluk Tiworo Kabupaten Muna Propinsi Sulawesi Tenggara. Jakarta.

Ditjen Kelautan, Pesisir, dan Pulau-Pulau Kecil (KP3K). 2007. Fasilitasi Sarana Pemanfaatan Biota Laut Yang Berkelanjutan di KKLD. Jakarta.

Direktorat Konservasi dan Taman Nasional Laut (KTNL). 2002. Inventarisasi dan Penilaian Potensi Calon Kawasan Konservasi Laut di Propinsi Sulawesi Tenggara. Kerjasama KTNL dengan LPM IPB. Jakarta.

Gaspersz, V. 1992. Analisis Sistem Terapan Berdasarkan Pendekatan Teknik Industri. Penerbit Tarsito. Ban-dung.

Jusuf, G. 1999. The Indonesian Fishery Policy. Proceedings of The $3^{\text {rd }}$ JSPS International Seminar on Fisheries Science in Tropical Area. Bali Island - Indonesia, 19 - 21 August 1999.

$\begin{array}{ccc}\text { Keputusan Menteri } & \text { Kelautan } & \text { dan } \\ \text { Perikanan } & & \\ \text { Nomor } & \text { Kep.10/Men/2002 } \\ \text { Tentang } & \text { Pedoman } & \text { Umum } \\ \text { Perencanaan } & \text { Pengelolaan } & \text { Pesisir } \\ \text { Terpadu. } & & \end{array}$

Malanesia, M. 2007. Analisis Unit Penangkapan Ikan Pilihan di Kabupaten Lampung Telukan, Buletin PSP. Vol. XVI. No. 3. IPB. Bogor.

Muhammadi, E. Aminullah, dan B. Soesilo. 2001. Analisis Sistem Dinamis. UMJ Press. Jakarta.

Mustaruddin dan Undang. 2005. Pedoman Pemanfaatan Biota Laut yang Berkelanjutan di Kawasan Konser-vasi Laut. Direktoral KTNL DKP RI. Jakarta.

Pemerintah Kabupaten Muna. 2006. Potensi dan Permasalahan Pengelolaan Wilayah Pesisir Kabupaten Muna - Sulawesi Tenggara. 2006.

Peraturan Pemerintah Nomor 15 Tahun 1990 tentang Usaha Perikanan sebagaimana telah diubah terakhir dengan Peraturan Pemerintah Nomor 141 Tahun 2001.

Peraturan Pemerintah Nomor 19 Tahun 1999 tentang Pengendalian Pencemaran dan/atau Pengrusakan Laut.

Putra, S. 2000. Konflik Pengelolaan Sumber Daya Kelautan di Sulawesi Utara Dapat Mengancam Kelestarian Pemanfaatannya. Jurnal Depdagri Vol 12. Jakarta.

Rancangan Peraturan Pemerintah tentang Konservasi Sumberdaya Alam. 2006

Surat Keputusan (SK) Bupati Kabupaten Muna No. 157 Tahun 2004 tentang penunjukan Teluk Tiworo dan Pulau-Pulau sekitarnya sebagai Kawasan Wisata Laut.

Undang-undang Nomor 5 Tahun 1990 tentang Konservasi Sumberdaya Alam dan Ekosistemnya.

Undang-undang Nomor 6 Tahun 1996 tentang Perairan Indonesia.

Undang-undang Nomor 31 Tahun 2004 tentang Perikanan.

Wagey, T. 2003. Mengelola Ikan Secara Bertanggung Jawab. http://wire.ap. org.

WWF Indonesia dan Yayasan ULI Peduli. Manajemen Penangkapan Ikan Karang Indonesia. Nuansabiru, Edisi 5. 